\title{
¿AUTONOMÍA VS. ORDEN PÚBLICO? EN LAS RELACIONES DE FAMILIA EN EL DERECHO ARGENTINO DESDE UNA PERSPECTIVA CONTEMPORÁNEA*
}

\author{
AUTONOMY VS. PUBLIC ORDER? IN FAMILY RELATIONSHIPS IN \\ ARGENTINIAN LAW FROM A CONTEMPORARY PERSPECTIVE
}
Marisa HerrerA $^{* *}$, María Martina Salituri AmezCuA ${ }^{* * *}$ y Carolina VIDETTA $^{* * * *}$

\begin{abstract}
Resumen: La transformación de las familias en la sociedad contemporánea argentina y el proceso de democratización vivenciado en su interior han impulsado una redefinición de las relaciones de autoridad y potenciado la participación, cada vez más respetuosa e igualitaria, de todos sus integrantes. Ello ha provocado una verdadera revolución en la última década, que se ve reflejada en la legislación. Así, la República Argentina cuenta desde el año 2015 con un nuevo Código Civil y Comercial de la Nación que ha podido seguir de cerca estas transformaciones. Asociado a la llamada constitucionalización y convencionalización del Derecho civil, se trata de un Código pensado para una sociedad multicultural (laica), basado en el principio de igualdad y no discriminación, que incorpora la obligada perspectiva de género, así como los paradigmas que moldean la consideración actual de los niños, niñas y adolescentes como sujetos de derechos con capacidad progresiva para su ejercicio. En este sentido, el objetivo del trabajo que nos proponemos realizar no solo consiste en poder individualizar las expresiones de la autonomía de la voluntad en el actual ordenamiento jurídico argentino dentro del Derecho de las familias, sino también analizar
\end{abstract}

* http://doi.org/10.15366/rjuam2018.38.001

Fecha de recepción: 31 de octubre de 2018.

Fecha de aceptación: 19 de diciembre de 2018.

** Doctora en Derecho, UBA. Investigadora Independiente, CONICET. Profesora Adjunta Regular, Facultad de Derecho, UBA. Profesora Titular, Facultad de Ciencias Económicas y Jurídicas, Universidad Nacional de La Pampa. Correo electrónico: marisaherrera12@gmail.com

${ }^{* * *}$ Abogada, UBA. Doctoranda en Derecho, UBA. Becaria doctoral, CONICET. Profesora, Facultad de Derecho, Universidad Nacional del Centro de la Provincia de Buenos Aires. Correo electrónico: msalituriamezcua@gmail.com

${ }^{* * * *}$ Abogada, especialista en Derecho de familia. Doctoranda en Derecho. Becaria doctoral, UBA. Ayudante de segunda en la materia Derecho de familia y sucesiones de la Facultad de Derecho, Universidad de Buenos Aires. Correo electrónico: carolinavidetta@gmail.com.

Esta publicación es realizada en el marco del Proyecto de Investigación CEAL (CEAL AL/2017-20) «La libertad de autodeterminación en las relaciones familiares y sus límites como desafío del Derecho de Familia en el siglo XXI en España y América latina», dirigido por Alma M. Rodríguez Guitián, concedido por la Universidad Autónoma de Madrid y Santander. 
los posibles límites de dicha autonomía de la voluntad tanto en las relaciones entre adultos/as como entre progenitores e hijos/hijas.

Palabras clave: Orden público, autonomía de la voluntad, familias, niños, niñas y adolescentes, Derecho argentino.

Abstract: The transformation of families in contemporary Argentinian society and the process of democratisation experienced within the country have prompted a redefinition of authority relations and enhanced participation of all its members, which is increasingly respectful and egalitarian. This has caused a real revolution in the last decade, which is reflected in the legislation. Thus, since 2015 the Argentinian Republic has a new Civil and Commercial Code of the Nation that has been able to closely monitor these transformations. Associated with the so-called constitutionalisation and conventionalisation of civil law, it is a Code designed for a multicultural (secular) society, based on the principle of equality and non-discrimination, which incorporates the obligatory gender perspective, as well as the paradigms that shape the current consideration of children and adolescents as subjects of rights with the progressive ability to exercise them. In this sense, the objective of the work that we propose to carry out is not only to be able to individualise the expressions of the autonomy of the will in the current Argentinian legal system within Family law, but also to carry out an analysis of the possible limits of said autonomy of the will in the relationships between adults and between parents and children.

Keywords: public order, autonomy of the will, families, children and adolescents, Argentinian law.

SUMARIO: I. INTRODUCCIÓN; II. RELACIONES DE FAMILIA ENTRE ADULTOS Y ADULTAS; 1 . Consideraciones generales. Análisis desde la obligada perspectiva de género; 2 . La figura de la compensación económica. Lo patrimonial como parte de la autodeterminación; 3. Violencia de género y Derecho civil: ¿cómo profundizar un feminismo emancipador?; III. RELACIONES ENTRE PROGENITORES E HIJOS/AS; 1. ¿Ser niños o niñas es igual a ser adultos o adultas? El principio de «autonomía progresiva»; A. Desde el sistema de protección de los derechos humanos; B. Autonomía y protección en el Derecho argentino: una relación complementaria; 2. El instituto de la responsabilidad parental; A. Consideraciones generales; B. Una relación inversamente proporcional; C. Progenitores adolescentes: ¿cómo ejercen sus derechos en relación con sus hijos e hijas?; 3. Autonomía progresiva y el derecho al cuidado del propio cuerpo de las personas menores de edad; A. Consideraciones generales; B. Un supuesto especial: ejercicio del derecho a la identidad de género de niñas, niños y adolescentes; IV. CIERRE A MODO DE CONCLUSIÓN: ¿QUÉ LIBERTAD Y QUÉ ORDEN PÚBLICO EN CONTEXTOS SOCIALES COMO LOS ACTUALES?; V. BIBLIOGRAFÍA.

\section{INTRODUCCIÓN}

Podemos afirmar que en la actualidad la autonomía de la voluntad en las relaciones familiares ha pasado a ser uno de los «temas estrella», tanto desde el ámbito legislativo como jurisprudencial y doctrinario, a niveles nacional e internacional. Puesto que implica 
el abordaje de las tensiones contemporáneas y complejas del Derecho de las familias ${ }^{1}$ entre lo público y lo privado, de allí el interrogante que encabeza el título del presente trabajo, es decir: ¿realmente la «autonomía de la voluntad» es un concepto jurídicamente antagónico al de «orden público»? ¿Acaso no podríamos analizarlos como complementarios?

La transformación de las familias en la sociedad occidental contemporánea y el proceso de democratización vivenciado en su interior han impulsado una redefinición de las relaciones de autoridad y potenciado la participación, cada vez más respetuosa e igualitaria de todos sus integrantes, implicando un proceso de «democratización de las relaciones familiares». Ello ha provocado una verdadera revolución en la última década, que se ve reflejada en los significativos cambios ocurridos en la actual legislación nacional.

Cabe aclarar, preliminarmente, que basaremos nuestro análisis y las respuestas a los interrogantes planteados a la luz del derecho argentino, principalmente, por dos motivos: 1) el anclaje de formación académica de las autoras, lo que permite brindar en un ámbito internacional una experiencia local abordada y estudiada en profundidad para aportar al análisis comparado; y 2) la entrada en vigencia desde mediados del 2015 de un nuevo Código Civil y Comercial (en adelante, $\mathrm{CCyC}$ ), con todo lo que implica la modificación integral de una codificación nacional de fondo en el siglo XXI, otorgando un fecundo escenario para el análisis jurídico contemporáneo a la luz de las renovadas complejidades sociales y de la jurisprudencia que, en estos tres años, se ha ido dictando en su consecuencia.

En este sentido, el CCyC ha podido seguir de cerca las contemporáneas transformaciones familiares, partiendo de la base de la llamada «constitucionalización y convencionalización del derecho civil $»^{2}$, se trata de un Código pensado para una sociedad multicultural y laica, asentado en los principios de igualdad, libertad y solidaridad, que incorpora la obligada perspectiva de género como estándar jurídico transversal, así como los paradigmas que moldean la consideración actual de los niños, niñas y adolescentes (en adelante, NNyA) como sujetos de derecho con capacidad progresiva para su ejercicio.

En suma, este Código es producto de una época de implosión legislativa, de ampliación de derechos, que visibiliza un mayor compromiso de la ley con la realidad social. Así, el CCyC comienza su articulado previendo la aplicación de sus normas de acuerdo a los tra-

1 Un importante sector de la doctrina nacional ha dejado de referirse al «Derecho de familia» en singular para, pasar a hablar de «Derecho de las familias» en plural. Ello, a fin de visibilizar a través de este cambio conceptual el reconocimiento expreso de la diversidad de formas familiares, así como de situaciones y relaciones entre sus miembros y con el Estado. Lo que permite, desde el reconocimiento de las diferencias y desigualdades fácticas (entre ellas las desigualdades socioeconómicas), la construcción de mecanismos de igualdad jurídica real, material o estructural, vid. HERRERA, M. (dir.), Manual de Derecho de las familias, Buenos Aires (Abeledo Perrot), 2015.

Vid. LORENZETTI, R., «Comentario a los artículos $1 .^{\circ}$ y $2 .{ }^{\circ} »$, en LORENZETTI, R. (dir.), Código Civil y Comercial de la Nación Comentado, Tomo I, Santa Fe (Rubinzal Culzoni), 2014, pp. 26-39; HERRERA, M. y CARAMELO, G., "Comentario a los artículos $1^{\circ}$ y $2^{\circ}$ », en HERRERA, M., CARAMELO, G. y PICASSO, S. (dirs.), Código Civil y Comercial de la Nación Comentado. Título Preliminar y Libro Primero, Ciudad Autónoma de Buenos Aires (Infojus), 2015, pp. 5-34. 
tados internacionales de derechos humanos. En su art. $1^{3}$ se establece el diálogo de distintas fuentes en la aplicación sistémica de las normas civiles, estipulándose que los casos que rige el Código deben ser resueltos de conformidad con los tratados de derechos humanos en los que la República sea parte. Y el art. $2^{4}$, al referirse a los parámetros de interpretación de la ley, vuelve a referirse a los instrumentos de derechos humanos. Dichos preceptos son considerados el nudo gordiano o columna vertebral del Derecho civil contemporáneo ${ }^{5}$, implicando re-negociaciones en la ancestral tensión entre «lo público» y «lo privado» ${ }^{6}$, explicitadas en los fundamentos del Anteproyecto ${ }^{7}$ que constituye el antecedente directo del CCyC.

En este sentido, el objetivo del trabajo que nos proponemos realizar no solo consiste en poder individualizar las expresiones de la autonomía de la voluntad en el actual ordenamiento jurídico argentino (específicamente dentro del Derecho de las familias), sino también en llevar a cabo un análisis de los posibles límites de dicha autonomía de la voluntad en la ancestral tensión con el orden público. Por lo que cabe preguntarnos: ¿cuál es la «dosis» justa de cada uno de estos principios en las distintas instituciones y figuras que involucran las relaciones de familia? ¿Es posible mantener categorías clásicas en sociedades cada vez más complejas, mientras a la par aparecen nuevas categorías contenedoras de las realidades contemporáneas? Es decir, ¿pueden coexistir organizaciones familiares tradicionales y modernas? En este contexto, el gran desafío implica discernir entre qué mantener y qué modificar en nuestros sistemas jurídicos a la luz del principio de realidad.

Para ello, dividiremos nuestra presentación en dos grandes partes: 1) desde las relaciones entre adultos/as y 2) respecto a las relaciones entre progenitores y sus hijos/as. Lo cual nos permitirá observar y comprender la dinámica de la autonomía de la voluntad entre los miembros de las familias desde dos ángulos de análisis bien distintos.

La delimitación del ámbito de la autonomía constituye, en definitiva, el reto básico al que se enfrenta hoy el Derecho de las familias. Es decir, debe buscarse un equilibrio razonable entre, por un lado, la necesaria intervención de los poderes públicos para la protección de aquellos derechos y garantías que conforman el orden público constitucional/convencional

\footnotetext{
3 «Los casos que este Código rige deben ser resueltos según las leyes que resulten aplicables, conforme con la Constitución Nacional y los tratados de derechos humanos en los que la República sea parte (...)».

4 «La ley debe ser interpretada teniendo en cuenta sus palabras, sus finalidades, las leyes análogas, las disposiciones que surgen de los tratados sobre derechos humanos, los principios y los valores jurídicos, de modo coherente con todo el ordenamiento».

5 AA. VV., El principio de autonomía progresiva en el Código Civil y Comercial. Algunas reglas para su aplicación, Buenos Aires (Infojus), 2015. Disponible en $<$ http://www.saij.gob.ar/aida-kemelmajercarlucci-principio-autonomia-progresiva-codigo-civil-comercial-algunas-reglas-para-su-aplicaciondacf150461-2015-08-18/123456789-0abc-defg1640-51 fcanirtcod>. [Consultado el 16/10/18].

6 Estas tensiones en la definición y delimitación entre «lo público» y «lo privado» en materia de familias se relacionan con el respeto a la intimidad familiar, por un lado, y con la intervención estatal justificada que garantice la igualdad real, por el otro; base, sobre la cual se asienta la relación entre familias y Estado.

7 Redactado por la Comisión integrada por los doctores Ricardo Luis Lorenzetti, Elena Highton de Nolasco y Aída Kemelmajer de Carlucci, en cumplimiento del Decreto Presidencial 191/2011.
} 
y, por otro, el respeto a la configuración de relaciones entre adultos/as y relaciones paterno/ materno-filiales fundamentadas en los principios de libertad, igualdad y solidaridad.

Asimismo, no podemos obviar que en dichas relaciones, y dependiendo de las circunstancias en las que se encuentren los distintos sujetos involucrados, puede partirse a veces de una situación fáctica de vulnerabilidad o desigualdad de uno de los miembros de la familia, de modo que la afirmación sin más de dicha autonomía puede generar ciertos abusos o determinados riesgos que el derecho no debe desconocer. De allí, la necesidad de buscar fórmulas jurídicas que, sin caer en un paternalismo arbitrario, tengan en cuenta el derecho a la autodeterminación de cada uno de sus miembros (adultos/as y NNyA).

Ahora bien, luego de esta introducción que nos enmarca y advierte sobre la importancia, complejidad y dinamismo de la temática escogida, pasamos a considerar cada una de las grandes áreas que nos hemos propuesto desde un abordaje contemporáneo sobre algunas de sus principales derivaciones.

\section{RELACIONES DE FAMILIA ENTRE ADULTOS Y ADULTAS}

\section{Consideraciones generales. Análisis desde la obligada perspectiva de género}

La tensión entre autonomía de la voluntad y orden público en las relaciones de familia ha ingresado por los vínculos jurídicos entre los/as adultos/as en torno a qué pueden resolver ellos/as por sí mismos/as, de manera consensuada, más allá o priorizándose esto por sobre lo que establece la ley que es tenido como régimen legal supletorio; es decir, excepto pacto o acuerdo en contrario. Qué respetar como clara manifestación de la libertad para decidir, y qué limitar por encontrase en juegos derechos humanos comprometidos, derechos de terceros o que exceden dicho campo de autonomía, constituye uno de los interrogantes clave del derecho que se amplifica cuando se trata del Derecho de las familias, cada vez más diverso y, por lo tanto, complejo.

Esta autonomía en el campo de las relaciones entre adultos/as, en particular, de pareja -bajo el ropaje o no de un matrimonio- ha pasado por diferentes estadios y consecuentes debates, en el que cada vez la libertad fue adquiriendo mayor peso y protagonismo. En este recorrido hacia una mayor apertura, siempre pregonando una visión crítica y contemporánea, se coloca en el centro de la escena la obligada perspectiva de género ${ }^{8}$. Nos explicamos.

8 Tantísimos son los instrumentos internacionales - tanto de hard law como de soft law- que revalorizan la perspectiva de género como pieza fundamental de la democracia que debe irradiar los ordenamientos jurídicos nacionales. Como síntesis de ello, cabe traer a colación la Recomendación General núm. 31 del Comité para la Eliminación de la Discriminación contra la Mujer y la Observación General núm. 18 del Comité de los Derechos del Niño sobre las prácticas nocivas, adoptadas de manera conjunta del 2014 en el que se expresa que

«[1] os Estados partes tienen la obligación de cuestionar y cambiar las ideologías y estructuras patriarcales que impiden a las mujeres y las niñas ejercer plenamente sus derechos humanos y libertades. Para que las mujeres y las niñas superen la exclusión social y la pobreza que muchas padecen y que incrementan su vulnerabilidad 
Acordar, consensuar, pactar implica que dos personas, en igualdad de condiciones y sin condicionamientos que puedan obstaculizar o viciar la voluntad, resuelvan del modo que lo crean conveniente, sus conflictos tanto en el plano personal como patrimonial y mixto; esto último, para aquellos/as autores/as que consideran que ciertos efectos como los alimentos y la vivienda comprometerían ambos componentes, personales y patrimoniales ${ }^{9}$. Ahora bien, qué lugar ha ocupado y ocupa la perspectiva de género para alcanzar esa igualdad que constituye un presupuesto básico para la validez de todo acto derivado de la libertad y autonomía como son los acuerdos. Atrás y a lo lejos han quedado esas normas en las cuales las mujeres eran consideradas incapaces de hecho relativas sujetas a la potestad marital, a quienes se les tenía vedada la facultad para decidir el domicilio conyugal, el ejercicio de la entonces «patria potestad» sobre sus hijos/as, o la posibilidad de que su apellido se encuentre presente en la identidad de los hijos/as ${ }^{10}$. Normas que han sido derogadas por impulso del desarrollo paulatino, sostenido y sólido de la visión de género en el campo de las relaciones de familia. Perspectiva que se complejiza aún más, si se tiene en cuenta otra transversalidad que ha revolucionado el ámbito en estudio como lo es la igualdad derivada de la orientación sexual ${ }^{11}$ al ampliar una institución clásica como el matrimonio a las parejas del mismo sexo y, por

a la explotación, las prácticas nocivas y otras formas de violencia por razón de género, es preciso equiparlas con las destrezas y competencias necesarias para hacer valer sus derechos, incluido el de adoptar decisiones autónomas e informadas sobre sus propias vidas. En este contexto, la educación es un instrumento importante para empoderar a las mujeres y las niñas de manera que reivindiquen sus derechos» (Comité para la Eliminación de la Discriminación contra la Mujer Observación General núm. 31 y Comité de los Derechos del Niño Observación General núm. 18 sobre las prácticas nocivas, adoptadas de manera conjunta, disponibles en: $<$ http://www.acnur.org/fileadmin/Documentos/BDL/2014/9925.pdf> [consultado el 15/10/2018];

y también lo expresado por la Comisión Interamericana de Derechos Humanos en diciembre del 2017 ante la grave decisión del Ministerio de Educación y Ciencias de Paraguay de prohibir la difusión y utilización de materiales referentes a la «teoría y/o ideología de género», al entender que ello supone un retroceso para los derechos de las mujeres, de las personas con orientaciones sexuales e identidades de género diversas y de los niñas y niños a recibir una educación libre de estereotipos basados en ideas de inferioridad o de subordinación. En ese sentido, se expuso que

«[e]ste tipo de medidas suponen una grave omisión del deber del Estado de proteger a la niñez de toda forma de violencia y de discriminación, en todos los ámbitos, y especialmente en la escuela», agregándose que es alarmante que «la perspectiva de género sea peyorativamente referida como "ideología de género". La perspectiva de género es una herramienta clave para combatir la discriminación y la violencia contra las mujeres y contra las personas con orientaciones sexuales e identidades de género diversas; y un concepto que busca visibilizar la posición de desigualdad y de subordinación estructural de las mujeres a los hombres en razón de su género» (Oficina de Prensa y Comunicación de la CIDH, «CIDH lamenta la prohibición de la enseñanza de género en Paraguay», disponible en: $<\mathrm{http}$ :/www.oas.org/es/cidh/ prensa/comunicados/2017/208.asp > . [Consultado el 16/10/2018].

9 Vid. HERRERA, M. (dir.), Manual de Derecho de las familias, cit., pp. 68-69.

10 Para una excelente síntesis sobre los principales cambios que ha sufrido el Derecho de familia y su consecuente pertinencia de ser denominado en plural (Derecho de las familias) en el que se demuestra el rol protagónico que ha tenido el desarrollo de los estudios de género en este campo del saber, vid. KEMELMAJER DE CARLUCCI, A., «Capítulo Introductorio», en KEMELMAJER DE CARLUCCI, A., HERRERA, M. y LLOVERAS N. (dirs.), Tratado de Derecho de familia, Tomo I, Santa Fe (Rubinzal Culzoni), 2014, pp. 9 y ss.

${ }_{11}$ Para profundizar sobre el impacto del reconocimiento de derechos a las parejas del mismo sexo en el sistema interamericano, se recomienda consultar la Opinión Consultiva núm. 24 de la Corte Interamericana de 
aplicación del mencionado principio de igualdad, con fuerza también en otras figuras como las denominadas en el derecho argentino «uniones convivenciales» ${ }^{12}$.

He aquí una nueva y moderna tensión que observan las relaciones jurídicas de familia entre adultos/as y que gira en torno a cómo profundizar la perspectiva de género cuando se parte del presupuesto que la interacción entre hombre-mujer ha dejado de tener exclusividad, compartiendo el escenario familiar con relaciones del mismo sexo ¿Acaso los vínculos de poder, sometimiento y verticalidad que rodean a las relaciones heterosexuales no pueden estar presentes en las relaciones homosexuales? Si la respuesta afirmativa se impone, aquí cabría dejar asentada la siguiente advertencia: la formación de los operadores jurídicos y no jurídicos, que también están tan presentes en la intervención con familias, debe tener la habilidad pertinente para detectar tales vínculos desiguales que, en definitiva, conculcan la libertad y autonomía y, por lo tanto, ponen en riesgo la posibilidad y virtudes de los acuerdos en la resolución pacífica de conflictos.

A los fines de seguir ampliando el foco en la mirada de género como eje revisionista y contemporáneo desde el cuál actualizar y fortalecer el equilibrio entre autonomía de la voluntad y orden público, es dable destacar que en el CCyC argentino, tal equidad en las relaciones de familia se encuentra condicionado por dos aspectos o consideraciones centrales: 1) el principio de solidaridad familiar enmarcado e interpelado por la noción de «vulnerabilidad», es decir, la protección a la persona más débil ${ }^{13} ;$ y 2) el principio de responsabilidad que se lo observa con mayor presencia en las relaciones entre progenitores e hijos/as que se analiza más adelante. Precisamente, la interacción ineludible entre vulnerabilidad y género incide de manera directa en uno de los principios rectores de las relaciones jurídicas de familia como lo es la solidaridad familiar. De allí, por ejemplo, que el art. 515 referido a las uniones convivenciales, en las que rige el principio de libertad ${ }^{14}$, expresa como «límites»

Derechos Humanos del 24/11/2017. Disponible en <http://www.corteidh.or.cr/docs/opiniones/seriea_24_esp. pdf $>$. [Consultado el 25/10/2018].

12 En el Derecho argentino, a las parejas que no se casan se les reconocen determinados derechos a nivel nacional, si cumplen con determinados requisitos. Al respecto, el art. 509 del Código Civil y Comercial con el que se inaugura el Título III del Libro Segundo dedicado a esta figura, dispone que: «[1]as disposiciones de este Título se aplican a la unión basada en relaciones afectivas de carácter singular, pública, notoria, estable y permanente de dos personas que conviven y comparten un proyecto de vida común, sean del mismo o de diferente sexo», agregándose como requisitos en el art. 510 que «[e]l reconocimiento de los efectos jurídicos previstos por este Título a las uniones convivenciales requiere que: a) los dos integrantes sean mayores de edad; b) no estén unidos por vínculos de parentesco en línea recta en todos los grados, ni colateral hasta el segundo grado; c) no estén unidos por vínculos de parentesco por afinidad en línea recta; d) no tengan impedimento de ligamen ni esté registrada otra convivencia de manera simultánea; e) mantengan la convivencia durante un período no inferior a dos años». La inscripción de las uniones convivenciales no es obligatoria sino a los efectos meramente probatorios (cfr. art. 511), excepto en materia de protección a la vivienda en defensa de los derechos de terceros.

13 Vid. Reglas de Brasilia sobre Acceso a la Justicia de las personas en Condición de Vulnerabilidad. Disponible en $<$ http://www.acnur.org/fileadmin/Documentos/BDL/2009/7037.pdf > . [Consultado el 25/10/2018].

$14 \mathrm{El}$ art. $513 \mathrm{CCyC}$ se refiere, precisamente, a la «autonomía de la voluntad de los convivientes» y dice que «[1] as disposiciones de este Título son aplicables excepto pacto en contrario de los convivientes. Este pacto debe ser hecho por escrito y no puede dejar sin efecto lo dispuesto en los artículos 519, 520, 521 y 522». 
generales que «los pactos de convivencia no pueden ser contrarios al orden público, ni al principio de igualdad de los convivientes, ni afectar los derechos fundamentales de cualquiera de los integrantes de la unión convivencial» $\mathrm{y}$, como limitaciones particulares, ciertos derechos que se regulan en protección al conviviente más vulnerable; es decir, por aplicación del mencionado principio de solidaridad familiar. Por lo tanto, no se puede pactar en contra del deber de asistencia mutua entre los/as convivientes (art. 519), el deber de contribución a los gastos del hogar (art. 520), la responsabilidad solidaria por las deudas contraídas para determinados fines ${ }^{15}$ (art. 521) y la protección de la vivienda familiar (art. 522).

La obligada perspectiva de género no solo marca el ritmo legal en cuanto a los derechos-deberes y efectos en las relaciones de pareja -matrimonial o convivencial-, sino también ha tenido su fuerte incidencia en el derecho argentino de adoptar un régimen de divorcio incausado, sin expresión de causa ${ }^{16}$. Sucede que tanto la noción de culpa en el marco de un divorcio culposo, subjetivo o contencioso, como establecer un lapso temporal determinado -ya sea desde la celebración del matrimonio y la separación de hecho-adoptándose causales de carácter objetivas, colaboraban a profundizar broncas, ataduras y violencia entre los/as cónyuges con fuerte repercusión negativa en los/as hijos/as cuando los/as hubiere. Por el contrario, el divorcio incausado permite que un/a cónyuge (divorcio unilateral) o ambos/as (divorcio bilateral) queden habilitados/as a peticionar el divorcio sin la necesidad de que se deba demostrar causa -subjetiva u objetiva alguna- fundada en el principio de libertad. Por lo cual, el matrimonio se celebra de a dos y se puede extinguir por voluntad de uno/a o ambos/as, porque ya, con que uno/a solo/a de los/as cónyuges no quiera seguir adelante con el proyecto de vida en común, el matrimonio no tiene razón de ser y la libertad se impone.

En definitiva, para alcanzar un correcto equilibrio entre autonomía de la voluntad y orden público en las relaciones de pareja es necesario, de base, tener muy presente la idea de igualdad real y para ello, a la vez, la obligada mirada de género y la consecuente noción de vulnerabilidad, los cuales constituyen componentes fundamentales desde el crisol de los Derechos Humanos.

15 Los arts. 519 a $522 \mathrm{CCyC}$ forman parte del llamado «piso mínimo obligatorio» y, por lo tanto, inderogable que se le reconoce también a los/as cónyuges. En lo que respecta a la responsabilidad solidaria por deudas, el art. $461 \mathrm{CCyC}$ al que se remite y que compromete al matrimonio, establece que se trata de deudas para solventar las necesidades ordinarias del hogar, el sostenimiento y educación de los hijos/as de conformidad con lo dispuesto en el art. $455 \mathrm{CCyC}$, es decir, tanto hijos/as comunes de los/as cónyuges, como de cada uno de ellos/as que conviven en el hogar conyugal/convivencial. Como se puede observar, la legislación civil argentina también contempla la llamada «familia ensamblada».

${ }_{16}$ Para una síntesis sobre el divorcio incausado en el régimen jurídico argentino, vid. HERRERA, M., «El régimen de divorcio incausado en el Código Civil y Comercial de la Nación», Suplemento Especial de Familia en el Código Civil y Comercial de la Nación (primera parte), diciembre, Buenos Aires (La Ley-Thomson Reuters), 2014, pp. 53 y ss., y HERRERA, M., «El lugar de la justicia en la ruptura matrimonial según la legislación que se avecina. Bases para leer el régimen de divorcio incausado» en GRAHAM, M. y HERRERA, M., (dirs.), Derecho de las familias, Infancia y Adolescencia. Una mirada crítica y contemporánea, Buenos Aires (Infojus-Ministerio de Justicia y Derechos Humanos de la Nación), 2014, pp. 275-323. 


\section{La figura de la compensación económica. Lo patrimonial como parte de la autodeterminación}

Es sabido que las rupturas de pareja traen consigo, entre otros tantos cambios, una mayor contracción o empeoramiento en la situación económica que repercute, como es de presumir, en el/la ex cónyuge o conviviente más vulnerable o con menos autonomía patrimonial. ¿Quiénes suelen quedar en esta situación de desventaja? Las mujeres y, en especial, cuando hay hijos/as, ya que ellas suelen ser las que resignan el desarrollo profesional para dedicarse al hogar si se siguen los cánones de estructuras familiares tradicionales, incluso también para aquellas más modernas siendo que aún existe una fuerte brecha en el mercado laboral en materia de inserción e ingresos entre hombres y mujeres ${ }^{17}$. ¿Cómo enfrentar desde la normativa esta desigualdad? Mediante figuras como la compensación económica que en el derecho argentino está habilitada tanto ante la ruptura de un matrimonio, como de una unión convivencial, más allá de algunas diferencias en su regulación. Tal como se deriva de lo dispuesto en el art. $441 \mathrm{CCyC}$ para el matrimonio y en el art. $524 \mathrm{CCyC}$ para las uniones convivenciales, esta institución es viable cuando el o la cónyuge (o conviviente) a quien el divorcio (o la unión convivencial) produce un desequilibrio manifiesto que signifique un empeoramiento de su situación y que tiene por causa adecuada el vínculo matrimonial (o unión convivencial) y su ruptura, tiene derecho a una compensación. Esta compensación puede consistir en una prestación única, una renta por tiempo determinado o, excepcionalmente, por plazo indeterminado solo para el caso de matrimonio, no así ante la ruptura de la unión convivencial. Además, puede pagarse con dinero, con el usufructo de determinados bienes o de cualquier otro modo que acuerden las partes o decida el juez ${ }^{18}$. Como la idea de la legislación civil y comercial es terminar con los efectos pendientes del matrimonio o las uniones convivenciales lo antes posible por las consecuencias no jurídicas que se deriva de quedar cuestiones pendientes, el plazo de caducidad para plantear la compensación económica está fijada en 6 meses desde la sentencia de divorcio o en el caso de las uniones convivenciales, desde su cese. Ahora bien, este es el principio que debería ceder cuando hay derechos en juego de mayor peso como lo es la protección al/a más vulnerable en razón del género; máxime, tratándose de una figura como lo es la compensación económica que se aplica, de manera preponderante, ante supuestos de desequilibrio económico que afecta a las mujeres tras la ruptura de la pareja. En otras palabras, es evidente que la lectura de la propia institución que ha sido gestada y edificada a la luz de la existente desigualdad real

\footnotetext{
17 «La brecha salarial de género» en la que se destaca que «en Argentina las mujeres ganan en promedio un 26 por ciento menos que los varones. Esta diferencia se registra en todas las categorías ocupacionales, y es aún mayor para los cargos de jefatura, donde la diferencia llega hasta un 30 por ciento en promedio», p.12, 17/06/2018. Disponible en $<$ https://www.pagina12.com.ar/128936-la-brecha-salarial-de-genero $>$. [Consultado el 25/10/2018].

18 Extensa es la bibliografía ya existente en torno a esta institución que introduce el Código Civil y Comercial, como síntesis de ella se recomienda consultar: MOLINA DE JUAN, M., Compensación Económica. Teoría y Práctica, Santa Fe (Rubinzal Culzoni), 2018.
} 
de género, debe ser interpretada más que ninguna otra, teniéndose en mira el principio pro debilis en favor de las mujeres ${ }^{19}$.

Un ejemplo elocuente de esta doble relación de fuerzas en materia de género que rodea a la compensación económica, se observa en un fallo de la Cámara de Apelaciones Civil, Comercial, Laboral y de Minería de Neuquén de fecha 06/07/2018 ${ }^{20}$. ¿Qué se debate en esta oportunidad? Si es posible aplicar este plazo de caducidad cuando la ruptura de la unión convivencial fue a causa de una situación de violencia de género. Con acierto, la Cámara revocó la decisión de la instancia anterior que había denegado el pedido de compensación al entender que se encontraba caduco el derecho, al entender que

«no se ha valorado desde una perspectiva de género cuál es la situación de las mujeres en relaciones afectivas con esta distribución de roles, fuera del matrimonio (...) no pueden soslayarse las particulares circunstancias que originaron el presente trámite. El cuadro de situación nos permite concluir que la Sra. M. se retiró de la vivienda como consecuencia del episodio denunciado, en un estado de confusión y vulnerabilidad, y a fin de proteger su propia integridad psico-física y la de su hija. Tal conducta, claramente, no responde a una decisión personal profunda y meditada sobre el cese de la convivencia».

En definitiva, la mirada de género no solo es hábil para revisar de manera profunda y compleja la noción de libertad y autonomía sino también, y a la par, para limitar esa supuesta libertad cuando no es tal debido a la situación de vulnerabilidad en la cuál se encuentran algunas mujeres. En esta línea, se podría sintetizar que no hay igualdad sin libertad, y tampoco hay libertad sin género, o si se siguen perpetuando las desigualdades en razón del género.

\section{Violencia de género y Derecho civil: ¿cómo profundizar un feminismo emancipador?}

Siguiéndose con una clara apuesta contemporánea, resulta de interés profundizar en uno de los nudos problemáticos más graves que se esgrimen dentro de las relaciones de pareja como lo es la violencia, en especial, la violencia de género. Al respecto, cabe aclarar que el régimen jurídico argentino adopta una postura civilista para abordar esta cuestión, más allá de que ciertos actos de violencia pueden configurar también delitos en la órbita penal y también deben ser tratados desde ese lugar.

\footnotetext{
19 Cfr. HERRERA, M., «El Código Civil y Comercial de la Nación desde la perspectiva de género», La Ley, 2015, Cita Online: AR/DOC/160/2015; HIGHTON, E., «Una etapa histórica: la mujer en el nuevo Código Civil y Comercial de la Nación», La Ley, Cita Online: AR/DOC/2598/2015; y MOLINA DE JUAN, M., «Justicia penal, perspectiva de género y violencia económica», La Ley, Cita Online: AR/DOC/1586/2017.

20 CApel. Civ., Com., Lab., Y Min., Sala I de Neuquén, «M. F. C. vs. C. J. L. s. Compensación económica», 06/07/2018, Cita Online: RC J 5312/18.
} 
Aclarado esto, cabe avanzar en algunos precedentes argentinos dictados durante los años 2017 y 2018 en los que se entrecruzan dos temáticas: 1) el incumplimiento alimentario como una situación de violencia ante el acreedor alimentario que suelen ser personas menores de edad y el consecuente doble esfuerzo por parte de las madres para llevar adelante distintas estrategias para sortear esa falta de aporte económico a los gastos cotidianos; y 2) el incumplimiento de medidas adoptadas en el marco de procesos de violencia. ¿Cuáles son las respuestas judiciales que se ordenan ante estas situaciones que comprometen, de manera más o menos directa, a las mujeres? en especial, cabe preguntarse si ellas son adecuadas en clave de que toda intervención estatal constituya un aporte emancipador/emancipatorio para las mujeres y no, por el contrario, que se las coloque en un lugar de mayor opresión.

De manera central, nos focalizamos en diferentes fallos emitidos por el Juzgado de Familia núm. 1 de Rawson, Provincia de Chubut, al ser de gran interés para interpelar la actuación de la justicia en este tipo de conflictos que comprometen relaciones de pareja desde la reiterada perspectiva de género. El primero, es un precedente del 01/09/2017 en el que una madre reclamara el pago de la obligación alimentaria por parte del padre. En ese marco, el juez intimó al padre a regularizar el pago mensual y abonar la deuda liquidada, bajo apercibimiento de decretar su exclusión de la vivienda que ocupa en carácter de medida conminatoria, verificándose algunos pagos parciales. Tras esto, la madre acompañó al expediente un instrumento en el que consta la cesión de derechos de facturación por el negocio de cerrajería del padre a favor de su hermano. Ante la demostración de esta situación de pretender despojarse del ingreso de bienes y así no cumplir con la cuota alimentaria, el juez procede a intimarlo al pago bajo apercibimiento de ordenar el cierre de la cerrajería. ¿Es el cierre de la fuente de trabajo y, por lo tanto, de los ingresos pertinentes para poder solventar la obligación alimentaria, una medida efectiva y eficiente? ¿Acaso no se podrían adoptar otras medidas que, además, no perjudiquen a los empleados de dicho negocio que si llegaran a tener hijos/as, esa es su fuente de trabajo y por ende de ingresos, para cumplir con sus propias obligaciones a cargo?

El segundo caso es del 19/09/201722 y encierra el incumplimiento por parte del agresor de la medida de restricción de acercamiento a la vivienda en la cual reside la ex mujer (víctima) y los/as hijos/as. En este supuesto, se dispone que si el autor incumple nuevamente con la restricción

«se incrementará automáticamente el perímetro a más de $200 \mathrm{~km}$. de la ciudad en carácter de medida cautelar, y ordenará sin más trámite a la Policía su arresto inmediato y traslado urgente a la zona limítrofe con la provincia vecina, para dejarlo en libertad en el puesto caminero de Gendarmería Nacional ubicado en un paraje de esa Provincia; asimismo, se le impone la sanción de cinco días de arresto en dependencia policial.

\footnotetext{
21 Juzgado de Primera Instancia de Familia de la Circunscripción Judicial de Rawson, «S. s/ Violencia familiar», 01/09/2017, Cita Online: elDial AAA145.

22 Juzgado de Primera Instancia de Familia de la Circunscripción Judicial de Rawson, «L. s. Violencia familiar», 19/09/2017, Rubinzal Online Cita: RC J 7622/17.
} 
Ello así, dado que si el agresor debe recorrer $200 \mathrm{~km}$. para vulnerar a la víctima, es indudable que la autoridad policial tiene mayores probabilidades de detenerlo antes de que cumpla con su propósito, ventaja que desaparece cuando ambas partes viven en una misma localidad y de dimensiones relativamente reducidas»».

Es decir, se adopta apercibimiento de deportación «frente al enorme desprecio a la autoridad del Poder Judicial que el agresor demuestra con su desobediencia, y al riesgo cierto de la mujer de sufrir un nuevo episodio de violencia grave, con efectos irreparables (...) al advertirse al victimario de su posible exposición a sufrir una suspensión temporal de su derecho constitucional de permanecer y transitar en esta región de la Provincia». Se advierte, en primer lugar, el desprecio hacia la autoridad judicial (al propio juez) por haber incumplido la orden dispuesta de restricción y, después, en la protección a la víctima. Es claro que desde la obligada perspectiva de género, la relevancia debería ser al revés, primero la víctima y después el desprecio por la autoridad judicial. Ahora bien, cabe preguntarse si la deportación de un agresor afuera de los límites de la provincia en la cuál se encuentra la víctima sería una medida hábil para el abordaje profundo y sostenido de la situación de violencia.

El tercer caso es de fecha 04/10/201723. Aquí quien demanda los alimentos es la abuela guardadora en representación de su nieto menor de edad y con problemas de salud. El juez le corre traslado al padre para «que formule su descargo sobre la situación de violencia familiar y de género originada en la falta de pago de la cuota alimentaria, previo a resolver la procedencia de medidas conminatorias y sanciones que pudieran corresponder (...) incluyendo el arresto»». Esta actitud cabe preguntarse si, más allá de la pertinencia de entender que todo incumplimiento alimentario constituye una situación de violencia en el sentido amplio del término, ¿ello convertiría a los procesos de alimentos en procesos de violencia? Entendemos que la respuesta negativa se impone. La perspectiva de género es hábil para profundizar sobre las consecuencias negativas del incumplimiento alimentario no solo en los hijos o hijas sino también en las madres; pero, no significa que deban ser abordados como procesos de violencia y dejen de ser considerados conflictos alimentarios. Más allá de esta observación, en este caso se ordena «intimar al demandado a que dentro del plazo de cinco días abone las cuotas alimentarias adeudadas, bajo apercibimiento de disponer como medida conminatoria la exclusión de cualquier vivienda que ocupe y dejarlo en situación de calle». Nuevamente, es dable preguntarse si el dejar a alguien en situación de calle y, por lo tanto, aplicar la mirada punitivista en el campo civil sería el mejor modo de resolver este tipo de conflictos. ¿Acaso la mujer quiere que el hombre deje de ejercer violencia hacia ella o que este quede en situación de calle?

El cuarto caso es del 08/02/2018 ${ }^{24}$ y también compromete una situación de violencia de género con la comprobación de violencia física por parte de la ex pareja, e intimidacio-

23 Juzgado de Primera Instancia de Familia de la Circunscripción Judicial de Rawson «T. c/ J. s/ Alimentos», 04/10/2017, Cita Online: elDial AAA257.

24 Juzgado de Primera Instancia de Familia de la Circunscripción Judicial de Rawson, «N. s/ Violencia familiar», 08/02/2018, Cita Online: elDial.com - AAA674. 
nes varias en la puerta de diferentes lugares donde concurre la víctima vigilándola con el auto. Ante el incumplimiento de la medida de restricción de acercamiento, el juez ordena el secuestro del auto en virtud de que

«aparece siempre un instrumento que es utilizado por el agresor como elemento facilitador de su estrategia de acecho y hostigamiento, agravando de ese modo su peligrosidad y el correlativo estado de vulnerabilidad de la mujer (...) L. aprovecha las ventajas de la movilidad y rapidez que le provee su automotor para acercarse y atemorizar a su ex pareja, y eventualmente escapar a toda prisa. (...) Como contrapartida, la mujer trabaja caminando en la vía pública, lo que se traduce en un grado de mayor exposición frente a un victimario motorizado».

En este caso, se observa que la medida adoptada guarda relación con la situación de violencia fundada en dos cuestiones: 1) es la herramienta intimidatoria que se utiliza; y 2) lo que implica como valor simbólico el auto para ciertas personas. Ahora bien, cabría preguntarse desde la obligada perspectiva de género si este tipo de intervenciones no podrían ser más profundas y, por lo tanto, emancipadoras para las víctimas con el consecuente empoderamiento que ello significa. En esta línea, nos preguntamos si no podría haberse ordenado que el auto fuera utilizado por la víctima y si ella no sabía conducir, la obligación del autor a pagar un curso para que la mujer aprenda a manejar sabiendo que al adquirir mayores conocimientos o aptitudes, se amplía el potencial y valorización de la persona. En otras palabras, que el auto como instrumento intimidatorio se convierta en un instrumento de mayor libertad, justamente, su opuesto.

En definitiva, proponer una perspectiva contemporánea y renovada de la tensión y equilibrio entre autonomía de la voluntad y orden público en las relaciones de pareja debe tomar como punto de partida la perspectiva transversal y compleja que trae consigo la mirada de género. Desde esta óptica, se han seleccionado algunas temáticas que han sido hábiles en el derecho argentino para movilizar ciertas estructuras tradicionales y actualizar algunos planteos y debates.

\section{RELACIONES ENTRE PROGENITORES E HIJOS/AS}

\section{1. ¿Ser niños o niñas es igual a ser adultos o adultas? El principio de «autonomía progresiva»}

\section{A. Desde el sistema de protección de los derechos humanos}

Para comenzar a tratar esta interpelación adelantamos que la respuesta negativa se impone, puesto que el sistema jurídico no puede tratar igual a lo que de base es distinto, 
toda vez que construir igualdad jurídica implica, necesariamente, empezar por reconocer y hacerse cargo de las desigualdades fácticas y sociales.

Al respecto, la Corte Interamericana de Derechos Humanos (en adelante, Corte IDH), máximo Tribunal regional, ha entendido desde hace varios años en su Opinión Consultiva (en adelante, OC) núm. 17/2002, sobre el estatus jurídico de NNyA, que «en razón de las condiciones en las que se encuentran los niños, el trato diferente que se otorga a los mayores y a los menores de edad no es per se discriminatorio, en el sentido proscrito por la Convención [Americana]. Por el contrario, sirve al propósito de permitir el cabal ejercicio de los derechos reconocidos al niño» (párr. 55).

Por lo que a los NNyA, el sistema jurídico les reconoce lo que se llama un «plus de derechos»; es decir, los derechos humanos que titularizan todas las personas, más los que les corresponden por su calidad de personas menores de 18 años de edad y en pleno desarrollo, lo que en el sistema regional interamericano implica la categoría de «medidas de protección especial» por parte de las familias, la sociedad y el Estado a las que se refiere el art. 19 de la Convención Americana sobre Derechos Humanos.

Ello implica, entonces, una tríada de relaciones equilibradas entre: 1) los derechos de los NNyA, ejercidos a la luz del principio de autonomía progresiva; 2) las obligaciones de los progenitores, establecidas a través del instituto de la responsabilidad parental; y 3 ) la responsabilidad del Estado como garante último de los derechos humanos, que se enmarca en el paternalismo jurídico o justificado.

Esta tríada, complementaria y tensional, implica en materia de capacidad de ejercicio por parte de las personas menores de 18 años de edad que: habrá derechos que podrán ser ejercidos solo por los $\mathrm{NNyA}$, otros para los que se requerirá representación, asistencia o colaboracion de sus progenitores $\mathrm{u}$ otras personas jurídicamente responsables, y, finalmente, otros casos en los que deberá ingresar la intervención justificada del Estado a través de alguno de sus poderes, principalmente el judicial, tomando decisiones para la protección de los derechos humanos y garantías fundamentales de los NNyA. En este sentido, podemos preguntarnos: ¿qué derechos podrían ejercer por sí solos los NNyA? ¿Es igual la situación de todos los NNyA o hay diferencias en cuanto a sus diversas edades y grados de madurez? ¿Cuándo se requeriría la actuación de los representantes legales y con qué alcances? ¿En qué situaciones se justifica jurídicamente la intervención estatal y bajo qué modalidades? Pues bien, dentro del marco de los referidos estándares de derechos humanos, las respuestas específicas y pormenorizadas a estos interrogantes las encontraremos en las regulaciones internas de los Estados, sobre todo a través de la rama del Derecho de las familias (a ello nos dedicaremos en los apartados siguientes de este trabajo).

Antes de ello, resulta indispensable explicitar qué se entiende por «autonomía progresiva». A nivel universal, la Convención sobre los Derechos del Niño (en adelante, CDN), se refiere a este principio y a sus derivaciones o efectos, de diferentes formas, a través de sus arts. 5, 12, 37, 40; así como también el Comité de Derechos del Niño al analizar 
pormenorizadamente el derecho a ser oído en su Observación General (en adelante, OG) núm. 12/2009 y en su OG núm. 20/2016 dedicada a los y las adolescentes. Asimismo, en el ámbito regional interamericano, cabe referir nuevamente la OC núm. 17/2002 de la Corte IDH y el fallo dictado por la misma en el caso «Atala Riffo vs. Chile», en el que también se profundiza en el derecho a ser oídas de las personas menores de 18 años de edad.

En definitiva, la $\mathrm{CDN}$ ha producido una resignificación de las relaciones paterno/ materno-filiales, sobre la idea de la democratización de las familias y de los vínculos entre adultos/as y niños/as, fundamentalmente, a través de su art. 5, que establece el deber y el derecho de los progenitores de impartir a sus hijos/as, en consonancia con la evolución de sus facultades, dirección y orientación apropiadas para que el/la niño/a ejerza los derechos reconocidos en el ordenamiento jurídico ${ }^{25}$. Se trata del principio de autonomía progresiva, de jerarquía constitucional/convencional, que «contempla las diferentes etapas por las que atraviesa el niño en su evolución psicofísica, determinando una gradación en el nivel de decisión al que puede acceder en el ejercicio de sus derechos fundamentales» ${ }^{26}$.

\section{B. Autonomía y protección en el Derecho argentino: una relación complementaria}

En primer lugar, cabe puntualizar que el ingreso del principio de autonomía progresiva ha sido paulatino y creciente. Numerosas legislaciones especiales a nivel nacional han sido la antesala o base sobre la que se apoyó, finalmente, la reforma estructural del Código de fondo en la materia. En este sentido, numerosas leyes fueron poco a poco introduciendo en sus regulaciones relativas a temáticas específicas las posibilidades de ejercicio de los derechos de NNyA de acuerdo al principio de autonomía progresiva que, como ya vimos, había ingresado a nuestro país a través de instrumentos internacionales sobre derecho humanos a los que se les otorgó jerarquía constitucional «en las condiciones de su vigencia $»^{27}$ (art. 75, inc. 22 de la Constitución Nacional).

Entre dichas leyes especiales, a nivel nacional, cabe mencionar las siguientes: Ley 25.673 (2003) de Programa Nacional de Salud Sexual y Procreación Responsable y su Decreto reglamentario 1.282/2003 (art. 4), Ley 26.061 (2005) de Protección Integral de Derechos de NNyA (arts. 2, 3, 24, 27), Ley 26.150 (2006) de Programa Nacional de Educación

25 Cfr. GIL DOMÍNGUEZ, A., FAMÁ, M.V. y HERRERA, M., Ley de Protección Integral de Niñas, Niños y Adolescentes. Derecho constitucional de familia. Comentada, anotada y concordada, Buenos Aires (Ediar), 2012, p. 171.

26 FERNÁNDEZ, S., «Responsabilidad parental y autonomía progresiva de niñas, niños y adolescentes», en FERNÁNDEZ, S. (dir.), Tratado de Derechos de Niños, Niñas y Adolescentes, Tomo I, Buenos Aires (Abeledo Perrot), 2015, pp. 666 y 667.

27 Lo que implica considerar la interpretación que de estos tratados realizan los organismos encargados de su aplicación y control, así por ejemplo, en lo que a esta temática respecta, las referidas OG del Comité de Derechos del Niño - a nivel universal-y la jurisprudencia y OC de la Corte IDH -a nivel regional interamericano(Cfr. Corte Suprema de Justicia de la Nación Argentina en casos: «Giroldi» (318:514), «Bramajo» (318:1940), «Mazzeo» (330:3248), «Carranza Latrubesse» (C. 568. XLIV y C. 594. XLIV), entre otros). 
Sexual Integral (art. 2), Ley 26.485 (2009) de Protección Integral a las Mujeres (arts. 24 y 28), Ley 26.529 (2009) de Derechos del Paciente en su Relación con los Profesionales de la Salud y su Decreto reglamentario 1089/2012 (art. 2), Ley 26.657 (2010) de Salud Mental (art. 26), Ley 26.743 (2012) de Identidad de Genero (arts. 5 y 11) y Ley 26.774 (2012) de Ciudadanía Argentina (art. 1).

Así, en el marco de este derrotero legislativo, llegó la oportunidad de la consagración del principio de autonomía progresiva con alcances generales a partir de la sanción de un nuevo $\mathrm{CCyC}$ y, con él, un renovado régimen de capacidad de las personas menores de edad (art. 25 CCyC). Comenzando con los conceptos jurídicos, la legislación civil actualmente vigente en Argentina establece que «menor de edad» es la «persona que no ha cumplido 18 años» $\mathrm{y}$, a continuación, el CCyC «denomina adolescente a la persona menor de edad que ha cumplido 13 años», incorporando en consecuencia una nueva categoría jurídica con efectos propios: la de los y las adolescentes.

En el siguiente artículo, el CCyC regula la capacidad de ejercicio de los NNyA (art. 26), sosteniendo que «la persona menor de edad ejerce sus derechos a través de sus representantes legales»-consagración del principio de protección especial-y que «la que cuenta con edad y grado de madurez suficiente puede ejercer por sí los actos que le son permitidos por el ordenamiento jurídico»-establecimiento del principio de autonomía progresiva-. Aclarándose que, en situaciones de conflicto de intereses con sus representantes legales, pueden intervenir con asistencia letrada; ingresando así al Código de fondo la figura del «abogado del niño», como garantía fundamental.

Al respecto, consideramos central focalizar en la vinculación y cruce entre sendos principios reconocidos por el artículo en análisis, el de protección especial y el de autonomía progresiva, entendiendo a los mismos como complementarios y no antagónicos. No es lo mismo un niño o niña de 3 años que un/a adolescente de $17^{28}$, y anular completamente la autonomía de ir tomando decisiones de los NNyA -sustituyéndolos completamente en su voluntad-para, a partir de los 18 años, otorgarles plena capacidad es una ficción fuertemente ortodoxa que no permite ir dándoles herramientas de acuerdo a sus aptitudes evolutivas. Por lo tanto, reconocer esta autonomía progresiva y acompañarlos en este proceso hacia la mayoría de edad de forma gradual es, sin lugar a dudas, una forma de protección.

La diferencia con el anterior régimen es notable, se deja atrás la categoría de incapacidad de hecho absoluta que colocaba, en principio, a toda persona menor de 14 años de edad

28 En este sentido, la Corte IDH ha dicho que, dentro de todo el grupo de personas menores de dieciocho años de edad, hay gran variedad de situaciones en relación con el grado de desarrollo físico e intelectual, la experiencia y la información que poseen los distintos sujetos, «la capacidad de decisión de un niño de 3 años no es igual a la de un adolescente de 16 años. Por ello debe matizarse razonablemente el alcance de la participación del niño en los procedimientos, con el fin de lograr la protección efectiva de su interés superior, objetivo último de la normativa del derecho internacional de los derechos humanos en este dominio» (Corte IDH, OC 17/2002, párr. 101). 
en una situación de anulación como sujeto de derecho activo (art. 54, inc. 2, Código Civil derogado), receptándose los principios de derechos humanos en la actual regulación civil.

Ahora bien, la gran pregunta que surge entonces para este nuevo Código de fondo es: ¿Cómo evaluar la autonomía? Este desafío ha sido enfrentado por el CCyC recurriendo a dos criterios simultáneamente, conforme surge de la disposición predecentemente transcripta en el art. 26. A saber, un criterio flexible que dependerá de cada niño/a o adolescente en particular, como lo es la alusión a la «madurez suficiente», y un criterio rígido comprobable matemáticamente, es decir la «edad». La conjunción de ambos parámetros exige de las y los operadores que deben interpretar y aplicar la norma la valoración de la condición individual de la persona para el supuesto de que se trate, o sea decisiones para «el caso a caso».

Por ende, no se podría a priori establecer un catálogo pétreo, absoluto y de alcances generales sobre todos los derechos que podrían ejercerse y a partir de cuándo. No obstante esta complejidad de la realidad -que exige decisiones ajustadas a las situaciones fácticas concretas-, el ordenamiento otorga algunas reglas generales y excepciones que emanan de los principios complementarios de autonomía y protección, brindando seguridad jurídica. Al respecto y, en primer lugar, cabe considerar la existencia de una presunción iuris tantum de autonomía para el ejercicio de derechos a partir de la adolescencia, así como la regulación específica de la capacidad de ejercicio para ciertos actos, como por ejemplo los que comprometen derechos personalísimos (y, dentro de estos, los de cuidado del propio cuerpo). Sobre algunos de estos actos en particular nos detendremos posteriormente en el marco de esta ponencia. Pero, antes de ello, corresponde preliminarmente enmarcar las reglas y disposiciones que rigen las relaciones de los NNyA con sus progenitores. Allá vamos.

\section{El instituto de la responsabilidad parental}

\section{A. Consideraciones generales}

En primer lugar, cabe considerar el cambio terminológico operado entre la actual y la derogada codificación. En este sentido, el régimen que regula los derechos y deberes entre progenitores e hijos/as menores de 18 años de edad pasó de denominarse «patria potestad» a «responsabilidad parental», visibilizando el verdadero eje que una regulación respetuosa de los derechos humanos pondera y prioriza en el marco de la democratización de las relaciones familiares, ya que aquello que los progenitores tienen respecto de sus hijos e hijas, más que poder, es una gran responsabilidad jurídica ${ }^{29}$.

En este sentido, emerge de los propios fundamentos del Anteproyecto de CCyC que la autonomía progresiva de NNyA ha permitido pasar de una noción de potestad o poder de los padres/madres sobre los hijos/as a la de responsabilidad, cuyo ejercicio requiere tener en consideración con respecto al hijo/a la evolución de sus facultades, para brindarle la

29 HERRERA, M. (dir.), Manual de Derecho de las familias, cit., p. 599. 
dirección y orientación apropiadas a fin de que ejerza los derechos que le son reconocidos (cfr. art. $5 \mathrm{CDN}$ ), y, así, pueda estar plenamente preparado para una vida independiente en sociedad y ser educado en el espíritu de los ideales proclamados en la Carta de las Naciones Unidas y; en particular, en un espíritu de paz, dignidad, tolerancia, libertad, igualdad y solidaridad (preámbulo de la $\mathrm{CDN}$ ).

De esta forma, el art. $638 \mathrm{CCyC}$ establece que «responsabilidad parental es el conjunto de deberes y derechos que corresponden a los progenitores sobre la persona y bienes del hijo, para su protección, desarrollo y formación integral mientras sea menor de edad y no se haya emancipado». Jurisprudencia ${ }^{30}$ dictada con posterioridad a la entrada en vigencia del CCyC ha ahondado en esta conceptualización y sus efectos, sosteniéndose que «la responsabilidad parental ya no tiene que ser pensada con una visión de "tutela" sino que su finalidad es la "protección" del hijo para su desarrollo y formación integral como persona. Esto implica que el derecho a la autodeterminación de los padres y la libertad para ejercer sus derechos sin injerencias estatales encuentra su límite en los derechos del niño». Por lo tanto, el Estado debe priorizar, en caso de conflicto, los derechos humanos y el interés superior del NNyA aun a costa del derecho de sus progenitores.

¿Qué sucede cuando los derechos e intereses de los NNyA y los de sus progenitores no son contrapuestos, sino que van en un mismo sentido y se implican mutuamente? ¿La figura del abogado del niño, en estos supuestos, debe ser necesariamente impuesta o se recurre a ella facultativamente? Veamos un caso que nos ayudará a echar luz a estos interrogantes. Se trata de un reclamo de alimento ${ }^{31}$ iniciado por la madre en representación de sus dos hijas adolescentes, M. (16 años) y F. (14 años), contra el padre de estas. El pronunciamiento de primera instancia es apelado por ambas partes. Llegadas las actuaciones al despacho de la Alzada esta observa que «no surge la presentación de las adolescentes M. y F. en los términos del art. $677 \mathrm{del} \mathrm{CCyC}$, es decir, su intervención en el proceso conjuntamente con la progenitora o de manera autónoma con asistencia letrada».

Es por ello que suspende el llamamiento de autos para dictar sentencia, disponiendo como «medidas para mejor proveer»:

«se remitan los autos a la instancia de origen a fin que, previo a dar curso a cualquier petición, se proceda a sanear la omisión indicada con la presentación formal de las adolescentes ya sea conjuntamente con su progenitora reclamante y ratificando todo lo actuado por ella con patrocinio letrado, o bien haciendo uso de la facultad que le confiere dicha norma, actuando autónomamente y con debida

$30 \quad$ Juzgado de Familia núm. 7 de Viedma, «Hospital Dr. Pedro Bianchi de Sierra Grande (POD) s/ Medida de Protección de derechos», 30/11/15. Disponible en <www.colectivoderechofamilia.com>. [Consultado el 22/10/2018].

31 Sala segunda de la Cámara de Apelación Civil y Comercial de Mar del Plata, «M. S. D. C/ G. P. E. s/ incidente de alimentos», 17/08/2017. Disponible en <www.colectivoderechofamilia.com>. [Consultado el $22 / 10 / 2018]$. 
asistencia letrada; a cuyos efectos deberán proporcionársele los medios necesarios.

III. Cumplido lo anterior, vuelvan los autos a esta Alzada».

Resulta que el art. 706 del CCyC prevé que las decisiones que se dicten en un proceso donde se encuentren involucrados NNyA deben tener en consideración el interés superior de éstos. Ello involucra, entre otros, el derecho a una defensa técnica a través de un abogado propio -abogado del niño- conforme lo prescribe el art. 707 del citado cuerpo normativo. A su vez, este artículo tiene su correlato con art. 677 del CCyC que establece, como regla general, que el/la adolescente cuenta con suficiente autonomía para intervenir en un proceso juntamente con sus progenitores o de manera autónoma con asistencia letrada. Con lo cual, fácil se infiere que se trata de una facultad de los/as adolescentes ya que es un derecho, y no una obligación. Por lo que consideramos que la sentencia comentada va en detrimento del interés superior de las adolescentes involucradas, toda vez que hacerlas cumplir con un requisito que claramente el $\mathrm{CCyC}$ no exige en un juicio donde lo que se reclama son nada más y nada menos que alimentos, implica retrasar el cobro de los mismos perjudicando sus derechos.

\section{B. Una relación inversamente proporcional}

Entre los principios que rigen el instituto de la responsabilidad parental, el CCyC (art. 639) enumera: a) el interés superior del niño; b) la autonomía progresiva del hijo conforme a sus características psicofísicas, aptitudes y desarrollo, puntualizándose que «a mayor autonomía, disminuye la representación de los progenitores en el ejercicio de los derechos de los hijos»; y c) el derecho del niño a ser oído y a que su opinión sea tenida en cuenta según su edad y grado de madurez.

En suma, podemos observar la consagración de principios constitucionales y convencionales de derechos humanos que orientan esta regulación tan fundamental del Derecho de las familias, así como el reconocimiento de una relación inversamente proporcional entre la autonomía progresiva y la figura de la representación. Por lo que mientras la primera va aumentando, de acuerdo a la edad y grado de madurez de los hijos e hijas, la sustitución de su voluntad por parte de los progenitores para el ejercicio de sus derechos y deberes (objeto por excelencia de la representación) va cediendo, lo que ha dado lugar a la aparición de nuevas figuras dentro de este rol parental como la «asistencia» que, sin anular a la persona menor de 18 años de edad, implica acompañarla en sus decisiones, partiendo de la idea de progresividad en el acceso a la autonomía y de protección como su complemento no antagónico.

Algunas reglas generales en la materia se refieren a la participación de los hijos e hijas menores de 18 años en asuntos que les afectan, patentizando el referido proceso de democratización de las relaciones familiares en el que se inspira el CCyC. Al respeto el art. 645 establece que, en todos los casos en que se requiere la intervención de ambos progenitores para la toma de decisiones (por ejemplo: autorización para contraer matrimonio, para salir 
del país, para ingresar a comunidades religiosas o para la administración de los bienes de los hijos), se exige también el consentimiento expreso del hijo o hija mayor de 13 años de edad.

Asimismo, se consagra el derecho de los hijos e hijas de ser oídos y participar en su proceso educativo, así como en todo lo referente a sus derechos personalísimos (art. 646 $\mathrm{CCyC}$ ). Por otra parte, en los supuestos excepcionales de cuidado personal unilateral (ya que el cuidado compartido es la regla en el actual CCyC), la opinión del hijo/a es una de las pautas legales a considerar para decidir judicialmente cual de los progenitores/as debe asumir esa función (art. 653 CCyC). Finalmente, sea cual sea la edad del hijo/a, los progenitores deben procurar su participación para la elaboración del plan de parentalidad al momento de la ruptura de la pareja de adultos (art. 655 CСуC).

\section{Progenitores adolescentes: ¿cómo ejercen sus derechos en relación con sus hijos e hijas?}

A diferencia de lo que ocurría en el anterior régimen, en el que los representantes legales de los progenitores adolescentes tenían un rol protagónico en la toma de decisiones respecto de sus nietos/as, el actual CCyC -enmarcándose en el referido cruce entre autonomía y protección- coloca como regla el ejercicio de derechos respecto de sus hijos/as en cabeza de los progenitores adolescentes, pero con ciertos límites y excepciones. Veamos.

El art. 644 establece que los progenitores adolescentes, estén o no casados, ejercen la responsabilidad parental de sus hijos e hijas pudiendo decidir y realizar por sí mismos las tareas necesarias para su cuidado, educación y salud. Mientras que se consagran dos grandes excepciones a esta regla: 1) las personas que ejercen la responsabilidad parental de los progenitores adolescentes que tienen a su cuidado un hijo o hija pueden oponerse a la realización de aquellos actos que resulten perjudiciales para el niño o niña; y 2) estas mismas personas se encuentran también legitimadas para intervenir cuando el progenitor omite realizar las acciones necesarias para preservar el adecuado desarrollo del niño o niña. Como podemos observar, en estos supuestos de excepción, la actuación de los abuelos y abuelas será subsidiaria frente conductas perjudiciales de los progenitores con respecto al hijo/a, tanto por acción como por omisión.

Por otra parte, aparece una aplicación específica de la figura de la asistencia a la que nos hemos referido anteriormente, al consagrarse que el consentimiento de los progenitores adolescentes debe integrarse con el asentimiento de cualquiera de sus propios progenitores si se trata de actos trascendentes para la vida del niño o niña, como la decisión libre e informada de su adopción, intervenciones quirúrgicas que pongan en peligro su vida u otros actos que puedan lesionar gravemente sus derechos. En caso de conflicto, es decir cuando no haya acuerdo entre progenitor/a y abuelo/a, la cuestión se resolverá a través de la intervención judicial, debiendo el juez decidir a través del procedimiento más breve previsto por la ley local, dada la transcendencia y urgencia de los actos sobre los que se debe fallar. 
Finalmente, el CCyC estipula que la plena capacidad de uno de los progenitores no modifica este régimen, ello sobre la base del principio de igualdad en el ejercicio de derechos respecto de los hijos e hijas, para los supuestos en que uno de los dos progenitores alcance la mayoría de edad antes que el otro u otra.

Consideramos que se trata de una regulación absolutamente respetuosa de la autonomía progresiva de los y las progenitores adolescentes, ya que el hecho de convertirse en padres/ madres a temprana edad no los hace adquirir per se la plena capacidad. Con lo cual se les permite el ejercicio de la responsabilidad parental pero con ciertos apoyos provenientes de sus propios progenitores, es decir, de los y las abuelos/as de sus hijos/as. Esto conlleva necesariamente la posibilidad de garantizar los derechos de sus hijos e hijas a ser criados y educados por sus propios progenitores, y a su vez apoyar al ejercicio parental de las personas menores de 18 años.

En esta línea, cabe traer a colación un fallo de la jurisprudencia nacional de fecha $27 / 10 / 2016^{32}$, respecto de una progenitora adolescente de 15 años de edad que se encontraba desde su embarazo conviviendo con su pareja (padre del bebé) en la casa de los padres de éste. La adolescente solicitó la percepción de la Asignación Universal por Hijo ${ }^{33}$ (AUH) por sí y por su hijo, que hasta el momento percibía su madre, en carácter de representante legal, sin que la joven conviviera con ella y sin hacerle entrega de esas sumas a la misma. Al tener en cuenta la capacidad progresiva de la adolescente, el Juzgado resolvió del siguiente modo:

«la joven P. cuenta con un grado de madurez suficiente para realizar por sí los actos que implican la percepción y la administración de las prestaciones que le corresponden por sí y por su hijo. Y es en tal oportunidad en que la representación legal prevista para esos actos concretos cede ante la autonomía de la adolescente. Circunstancias que no pueden soslayarse en tanto y en cuanto determinan en esta instancia, que resulta ser el mejor interés de la joven y su hijo».

Sin embargo, dado que autonomía y protección no son antagónicas, el a quo sostuvo que

«la historia vital y la situación familiar permiten pensar en que P. presenta un alto grado de vulnerabilidad, y sugieren la orientación, apoyo y seguimiento del Servicio de Protección de Derechos para fortalecer el rol materno, propiciar la inclusión laboral y la resolución del aspecto habitacional. Consideran pertinente

32 Juzgado de Familia núm. 2 de Esquel, «U., P. F. y A., N. s/ Medida Cautelar», 27/10/2016. Disponible en $<$ www.colectivoderechofamilia.com $>$. [Consultado el 22/10/2018].

33 La asignación universal por hijo/a (AUH) para protección social es un seguro social que se otorga en Argentina a personas desocupadas, que trabajan en el mercado informal o que ganan menos del salario mínimo, vital y móvil, consistente en un beneficio económico por cada hijo/a menor de 18 años de edad o hijo/a con discapacidad. Entró en vigor en el año 2009 por el Decreto del Poder Ejecutivo 1602/09. 
que se haga lugar al requerimiento impulsado por la Asesoría de Familia en tanto la joven puede administrar su dinero y resulta indispensable para su subsistencia y la de su hijo».

De esta manera, se puede observar la complementariedad entre autonomía y protección en el caso de progenitores adolescentes, ya que, por un lado, la joven cobra y administra ambas AUH, pero por el otro la protección estatal justificada no desaparece, sino que busca construir su empoderamiento.

\section{Autonomía progresiva y el derecho al cuidado del propio cuerpo de las personas menores de edad}

\section{A. Consideraciones generales}

¿De qué sirve reconocer a los NNyA como sujetos de derechos sino se crean condiciones para que ellos/as mismos/as puedan ejercer los derechos de los que son titulares? Tal como venimos sosteniendo a lo largo del presente ensayo, el CCyC -en materia de niñez y adolescencia- no solo que supera el test de constitucionalidad y convencionalidad -al reconocer a los NNyA como verdaderos sujetos de derechos- sino que vas más allá de ello. Es decir que, no se queda en el reconocimiento liso y llano, sino que se encarga de diseñar el sistema de capacidad de ejercicio de la persona menor de edad.

Así, el mencionado art. 26 diferenciando entre los derechos involucrados, esto es, si se trata de un derecho patrimonial donde están involucrados derechos de terceros o, por el contrario, si se trata de derechos personalísimos y, por lo tanto, entramos dentro del principio de reserva conforme al art. 19 de la Constitución Nacional, traza un sistema coherente con los principios que rigen la relación entre progenitores y sus hijos/as. Por lo que, frente a un derecho personalísimo como es el cuidado del propio cuerpo y que involucra prácticas y procedimientos tan disimiles como complejos, el CCyC no quiso dejar lugar a dudas sobre el ejercicio de derechos de NNyA.

De este modo, la segunda parte del art. 26 establece la presunción -siempre iuris tantum - de la capacidad de las y los adolescentes para el cuidado de su propio cuerpo. Distinguiendo según se trate de adolescentes de entre 13 y 16 años, o mayores de 16 años, y también del tipo de tratamiento, esto es: invasivo o no invasivo. Para el supuesto de adolescentes entre 13 y 16 años tratándose de un acto invasivo se requiere que la/el adolescente preste su consentimiento con la asistencia de sus progenitores, mientras que en los casos que sean no invasivos basta con el consentimiento del/a adolescente. Y, en el último párrafo, este artículo contempla la situación de los/as adolescentes a partir de 16 años, considerándolos como un/a adulto/a para las decisiones sobre el cuidado de su propio cuerpo.

Un dato no menor que se debe tener en cuenta al pensar en el cuidado del propio cuerpo de NNyA, es que se hallan en juego sus esenciales derechos humanos, tales como: el derecho 
a la vida, a la integridad psicofísica, a la salud, a la autonomía personal, a la intimidad y a la información. Además, al enmarcarse la cuestión en el campo de la bioética, el concepto tradicional de capacidad -civil- pierde peso y da lugar a otro concepto acorde con los derechos humanos en juego como el de competencia o mayoría médica anticipada para el acto médico. A partir del resonado caso Gillick ${ }^{34}$ se configuró una nueva categoría de $\mathrm{NNyA}$ «Gillick competent» constituida por quienes, sin contar con la edad que los ordenamientos legales establecen para prestar un consentimiento válido, pueden hacerlo en función de su grado de madurez o desarrollo ${ }^{35}$.

¿Qué se analiza a través de la competencia? La aptitud del paciente -pediátrico-para comprender la situación a la que se enfrenta, los valores que están en juego y los cursos de acción posibles con las consecuencias previsibles de cada uno de ellos para, a continuación, tomar, expresar y defender una decisión que sea coherente con su propio proyecto de vida y escala de valores ${ }^{36}$.

Ahora bien, la competencia bioética no es algo que se tenga o no se tenga o que se adquiera de un momento a otro, sino que sienta sus bases en la relación y la confianza entre el paciente y el equipo de salud y en la relación con su familia. Por otra parte, dicha competencia debe ser valorada en el caso concreto y varía en función de la madurez del NNyA y de la entidad de la actuación a que sea sometido, es decir, la competencia bioética se evalúa en función de un sujeto determinado, frente a una situación determinada y un tratamiento determinado. A su vez, dependiendo del tipo de tratamiento médico de que se trate será el grado de competencia que se requiera, es decir, no es lo mismo tratar una amigdalitis que rechazar un tratamiento oncológico ${ }^{37}$.

Asimismo, la competencia esta íntimamente relacionada con el derecho a la información a fin de que los NNyA puedan prestar el correspondiente consentimiento informado,

34 Es un leading case del año 1985 decidido por la Cámara de los Lores. En Inglaterra había comenzado a plantearse el problema de la distribución de anticonceptivos a personas que no habían llegado a los 16 años. La Sra. Gillick, madre de cinco hijas menores de 16 años, luego de presentar notas a la Administración solicitando que le aseguraran que no le distribuirán los mismos a sus hijas sin su consentimiento y sin repuesta alguna, se presentó a la justicia a fin de obtener la declaración pretendida. La decisión determinó que los derechos de los progenitores existen solo para beneficio de los hijos y para permitirles cumplir sus deberes; que el derecho de los progenitores a elegir si sus hijos seguirán o no un tratamiento médico concluye cuando los hijos están en condiciones de aprehender la opción propuesta. Las condiciones que deberían darse se basan en ciertos criterios tales como la madurez, el entendimiento y una evaluación del mejor interés del NNyA (Vid. Gillick v. West Norfolk and Wisbech Area Health Authority [1986] 1 AC 112 «Gillick»).

35 HIGHTON DE NOLASCO, E., «Los jóvenes o adolescentes en el Código Civil y Comercial», La Ley, 2015. Disponible en <http://www.nuevocodigocivil.com/los-jovenes-o-adolescentes-en-el-codigo-civil-ycomercial-por-elena-i-highton/>. [Consultado el 23/10/2018].

36 Juzgado de Primera Instancia Civil, Comercial, Conciliación y Familia, Villa Dolores, Córdoba, 21/09/2007, «C. J. A. y otra s/solicitan autorización», LLC 2007 -noviembre-, 1102.

37 LAMM, E., «El derecho de niños, niñas y adolescentes al cuidado de su propio cuerpo. Una cuestión de autonomía, libertad, integridad, libre desarrollo de la personalidad y dignidad», en FERNÁNDEZ, S., (dir.), Tratado de Derechos de Niños, Niñas y Adolescentes, Tomo I, cit., pp. 239-299. 
que ha sido definido como «una declaración de voluntad efectuada por un paciente quien, luego de recibir información suficiente referida al procedimiento o intervención quirúrgica que se le propone como médicamente aconsejable, decide prestar su conformidad y someterse a tal procedimiento o intervención luego de haber recibido información suficiente al respecto» ${ }^{38}$.

Por otra parte, observamos que esta vinculación entre cuidado del propio cuerpo y bioética obligó al legislador a echar mano a conceptos jurídicos indeterminados, como son «tratamiento invasivo»/«tratamiento no invasivo». ¿Acaso cómo debemos interpretar estos términos $?^{39}$ Para traer luz sobre ellos, el Ministerio de Salud de la Nación emitió la Resolución 65/2015 de fecha 9 de diciembre de 2015, luego de llevarse a cabo una mesa de trabajo denominada «Nuevo Código Civil y Comercial. Lectura desde los Derechos Sexuales y Reproductivos» de la que participaron especialistas ${ }^{40}$ en la temática e integrantes de equipos de diversas áreas del entonces ${ }^{41}$ Ministerio de Salud de la Nación. Entre los consensos logrados, se estableció que «el criterio de "invasividad" utilizado por el artículo $26 \mathrm{CCyC}$ debe leerse como tratamientos de "gravedad que impliquen riesgo para la vida o riesgo grave para la salud" ${ }^{2}$ (...) Por tanto, es de comprensión de este Ministerio que ampliar el tipo de tratamientos contemplados en la excepción a la presunción de la capacidad, es restrictivo del derecho a la salud integral e injustificado». Al mismo tiempo, se determinó que «la evaluación del riesgo de las prácticas sanitarias debe realizarse con base en evidencia científica» ${ }^{43}$. Agregando que «el riesgo de una práctica sanitaria es generalmente definido como la probabilidad de que se produzca un resultado adverso o como un factor que aumenta esa probabilidad».

Por lo tanto, «las prácticas sanitarias que requieren acompañamiento para la decisión en el período comprendido entre los 13 y los 16 años, son aquellas en las que existe evidencia científica que muestre una probabilidad considerable (alta) de riesgo o se generen secuelas físicas para el NNA y no solo en aquellas que tal consecuencia pudiera existir».

Y, específicamente en relación con las prácticas de salud sexual y salud reproductiva, los especialistas han consensuado que aquellas técnicas en general y todos los métodos anticonceptivos transitorios en particular (incluyendo los implantes y los dispositivos in-

38 WIERZBA, S., «La salud en el nuevo Código Civil y Comercial de la Nación» (En Letra), Dossier sobre el Código Civil y Comercial de la Nación, año II, núm. 4, tomo I, 2015. Disponible en $<\mathrm{http} / /$ www.fmed.uba. ar/depto/medlegnew/cod1.pdf $>$. [Consultado el 22/10/2018].

39 Para profundizar vid. FERNANDEZ, S., HERRERA, M. y LAMM, E., «El principio de autonomía progresiva en el campo de la salud», Revista La Ley, núm. 226, 2017, Cita Online: AR/DOC/2904/2017.

40 Entre los especialistas se destacan: Nelly Miyersky, Eleonora Lamm, Marisa Herrera, Silvia E. Fernández, Paola Bergallo, Sonia Ariza Navarrete, Gustavo Gallo, Emiliano Litardo, Iñaki Regueiro de Giacomi, Mercedes Monjaime y Verónica González Bonet, entre otros.

${ }_{41}$ El 5 de septiembre de 2018 pasó a ser una Secretaría del Ministerio de Salud y Desarrollo Social por Decreto 801/2018 del Poder Ejecutivo.

42 El subrayado nos pertenece.

43 El subrayado nos pertenece. 
trauterinos DIU) no son prácticas «invasivas que comprometan el estado de salud» en los términos del art. 26 del CCyC. Por lo tanto, los y las adolescentes, pueden acceder a los métodos anticonceptivos transitorios en forma autónoma, como también al diagnóstico de VIH y al test de embarazo.

Cabe destacar finalmente que el art. 26 dispone que, en caso de conflicto entre la opinión del/a adolescente y sus progenitores ${ }^{44}$, se resuelve teniendo en cuenta su interés superior, sobre la base de la opinión médica respecto a las consecuencias de la realización o no del acto médico.

\section{B. Un supuesto especial: ejercicio del derecho a la identidad de género de NNyA}

Argentina cuenta desde el año 2012 con la Ley 26.743 de Identidad de Género, lo que implicó reconocer y garantizar a toda persona el derecho al reconocimiento de su identidad de género; al libre desarrollo de su persona conforme a su identidad de género; $y$ a ser tratada de acuerdo con su identidad de género y, en particular, a ser identificada de ese modo en los instrumentos que acreditan su identidad respecto de el/los nombre/s de pila, imagen y sexo con los que allí es registrada, según reza el art. 1 de dicha ley.

De conformidad con los Principios de Yogyakarta ${ }^{45}$, la ley parte del reconocimiento de la identidad de género como:

«la vivencia interna e individual del género tal como cada persona la siente, la cual puede corresponder o no con el sexo asignado al momento del nacimiento, incluyendo la vivencia personal del cuerpo. Esto puede involucrar la modificación de la apariencia o la función corporal a través de medios farmacológicos, quirúrgicos o de otra índole, siempre que ello sea libremente escogido. También incluye otras expresiones de género, como la vestimenta, el modo de hablar y los modales» (cfr. art. 2).

En este sentido, es menester resaltar que se trata de una ley que reconoce la identidad de género como un derecho humano y, a su vez, representa un avance en la despatologización y desjudicialización.

\footnotetext{
44 Respecto del término progenitores, utilizado por el artículo 26 CCyC, la Resolución 65/2015 comentada dispone que no debe entenderse de forma restringida este concepto sino con un criterio amplio, que incluya a personas que ejerzan roles de cuidado formal o informalmente. De esta manera, cualquier «allegado» (art. 59 CCyC) o «referente afectivo» (art. 7 Dec. 415/2006 reglamentario de la Ley 26.061) podría asistir al NNyA en el consentimiento de dichos actos.

45 Principios de Yogyakarta: principios sobre la aplicación de la legislación internacional de derechos humanos en relación con la orientación sexual y la identidad de género, ONU, 26 de marzo de 2007. Disponible en <http://www.refworld.org/cgi-bin/texis/vtx/rwmain/opendocpdf.pdf?reldoc=y\&docid=48244e9f2>. [Consultado el 22/10/2018].
} 
Ahora bien, en lo que respecta puntualmente al ejercicio del derecho a la identidad de género de las personas menores de edad, la Ley 26.743 contiene dos normas de directa aplicación, diferenciando según se trate de solicitar la rectificación registral del sexo, el cambio de nombre de pila e imagen (art. 5), o acceder a intervenciones quirúrgicas totales y parciales y/o tratamientos integrales hormonales para adecuar su cuerpo, incluida su genitalidad, a su identidad de género autopercibida (art. 11). Esto implica, entonces, reconocer que los NNyA tienen derecho tanto a readecuar «sus papeles» a su identidad autopercibida como a tratamientos médicos para adecuar su cuerpo físico. ¿De qué manera? En el primer supuesto la petición debe ser efectuada a través de sus representantes legales y con expresa conformidad del niño/a o adolescente, que a su vez debe contar con la asistencia del abogado del niño.

Se trata de un procedimiento administrativo y solo para el caso que, por cualquier causa, se niegue o sea imposible obtener el consentimiento de alguno/a de los/as representantes legales del niño/a o adolescente, se podrá recurrir a la vía judicial para que los/as jueces/zas correspondientes resuelvan. Al respecto, ¿existe algún límite etario para el ejercicio de este derecho? La respuesta negativa se impone, puesto que los principios que rigen la cuestión son los de capacidad progresiva e interés superior del niño/ $\mathrm{a}^{46}$.

Por otra parte, cabe señalar que la Corte IDH en su reciente Opinión Consultiva sobre Identidad de género, e igualdad y no discriminación a parejas del mismo sexo del 2017, ha dicho que «como un ejemplo de una buena práctica con relación a este tema, el Tribunal no puede dejar de hacer mención a la Ley 26.743 de 23 de mayo de 2002 de Argentina "sobre el derecho a la identidad de género de las personas" cuyo artículo 5 se refiere al trámite de rectificación registral del sexo, el cambio de nombre de pila e imagen de niñas y niños» (párr. 156) ${ }^{47}$.

Ahora bien, tratándose del segundo supuesto, es decir, que una persona menor de edad pretenda someterse a una intervención quirúrgica dirigida a la reasignación sexual, la protección especial aumenta dada la irreversibilidad de la decisión. En función de ello, la ley establece para estos supuestos, además de los requisitos del art. 5, «...la conformidad

46 Cabe mencionar el resonado caso «Lulú» por ser la primera niña trans en el mundo que consiguió -sin acudir a la justicia- adecuar su documento de identidad de acuerdo a su identidad autopercibida. Para más información vid., entre otros: <http://www.revistaanfibia.com/cronica/nunca-es-el-cuerpo-equivocado/>; $<$ https://www.pagina12.com.ar/diario/sociedad/3-225462-2013-07-28.html >; <https://elpais.com/ sociedad/2013/10/09/actualidad/1381350842_204659.html >; [Consultado el 22/10/2018]. A este primer caso le han seguido otros, así se ha observado que «[a]l mes de marzo del año 2016 eran diez las personas menores de doce años que lograron adecuar su identidad de género en sus documentos, y muchas más mayores de dicha edad». SALDIVIA MENAJOVSKY, L., «Tomándose la despatologización en serio: el derecho a la identidad de género de niñxs y adolescentes», Revista Interdisciplinaria de Doctrina y Jurisprudencia. Derecho de familia, núm. 82, Buenos Aires (Abeledo Perrot), 2017, Cita Online: AP/DOC/894/2017).

47 Corte Interamericana de Derecho Humanos, Opinión Consultiva OC-24/17 de fecha 24 de noviembre de 2017 sobre Identidad de género, e igualdad y no discriminación a parejas del mismo sexo. Disponible en $<$ http://www.corteidh.or.cr/docs/opiniones/seriea_24_esp.pdf >. [Consultado el 22/10/2018]. 
de la autoridad judicial competente de cada jurisdicción, quien deberá velar por los principios de capacidad progresiva e interés superior del niño o niña...». Por lo tanto, para estos supuestos, sí se exige autorización judicial.

En este punto, corresponde preguntarnos: ¿cómo compatibilizamos las normas de la ley especial 26.743 y el art. 26 del CCyC? Ello en función de que chocan dos reglas generales del derecho de fuerte raigambre sintetizadas en los aforismos tradicionales: ley posterior prima sobre ley anterior y ley especial sobre ley general. La mencionada Resolución 65/2015 nos brinda una respuesta al respecto, sobre la base de entender que lo relativo a la identidad de género se encuadra en la categoría jurídica de cuidado del propio cuerpo; por ende,

«dado que se considera que las prácticas de modificación corporal relacionadas con la identidad auto-percibida son prácticas de cuidado del propio cuerpo, reguladas en el art. 26 del Cód. Civ. y Com., se descarta la aplicación del criterio etario de la ley especial (LDIG), en pos de una armonización constitucional y convencional de los criterios para la presunción de capacidad de adolescentes. Por ello, la interpretación normativa de acuerdo con los principios constitucionales pro personce y pro minoris implica preferir la aplicación del artículo 26 del Cód. Civ. y Com. que resulta más protectorio del ejercicio de los derechos de NNyA».

Esta solución, sin dudas, es la que más se ajusta a la perspectiva de derechos humanos y de género que debe primar en la interpretación y aplicación de nuestras normas.

\section{CIERRE A MODO DE CONCLUSIÓN: ¿QUÉ LIBERTAD Y QUÉ ORDEN PÚBLICO EN CONTEXTOS SOCIALES COMO LOS ACTUALES?}

Es sabido que el Derecho no es una ciencia exacta y mucho menos aquellos ámbitos del Derecho directamente comprometidos con el dinamismo y el movimiento constante y sonante de la realidad social, en particular, las relaciones de familia.

Un estudio profundo y contemporáneo de la tensión ancestral ente autonomía y orden público obliga a advertir, profundizar e intervenir teniendo en cuenta la interdependencia de los derechos humanos, es decir de los derechos civiles y los derechos sociales. Asimismo, nos conmina a estar a la altura de una sociedad cambiante, plural, multicultural e inclusiva, que nos llama a profundizar la mirada laica y humanista del derecho.

En este sentido, la obligada perspectiva de género y el reconocimiento de la autonomía progresiva de NNyA han sido los dos ejes transversales que hemos escogido para analizar, respectivamente, cada una de las dos grandes áreas en que se divide este trabajo: relaciones entre adultos/as y entre progenitores e hijos/as. Ello así, ya que la consagración de estos dos principios constituye un avance superlativo en el contemporáneo Derecho de las familias a la luz de los derechos humanos. 
Sin perjuicio de ello y, al mismo tiempo, sobre la base indispensable de su reconocimiento, resta no obstante advertir que la responsabilidad del Estado como garante último de los derechos humanos no termina allí. Sino que al reconocimiento se le debe sumar el ejercicio concreto en el día a día, y esto no se logra sino a través de políticas públicas que acompañen a todas las personas -especialmente a las más vulnerables-, desde sus diferentes realidades, para que puedan tener oportunidades reales de ejercer sus derechos.

\section{BIBLIOGRAFÍA}

FERNÁNDEZ, S., «Responsabilidad parental y autonomía progresiva de niñas, niños y adolescentes», en FERNÁNDEZ, S. (dir.), Tratado de Derechos de Niños, Niñas y Adolescentes, Tomo I, Buenos Aires (Abeledo Perrot), 2015, pp. 659-699.

GIL DOMÍNGUEZ, A.; FAMÁ, M. V., y HERRERA, M., Ley de Protección Integral de Niñas, Niños y Adolescentes. Derecho constitucional de familia. Comentada, anotada y concordada, Buenos Aires (Ediar), 2012.

HERRERA, M. «El Código Civil y Comercial de la Nación desde la perspectiva de género», La Ley, 2015, Cita Online: AR/DOC/160/2015.

HERRERA, M. (dir.), Manual de Derecho de las familias, Buenos Aires (Abeledo Perrot), 2015.

HERRERA, M. y CARAMELO, G., «Comentario a los artículos $1 .^{\circ}$ y $2 .{ }^{\circ} »$, en HERRERA, M., CARAMELO, G. y PICASSO, S. (dirs.), Código Civil y Comercial de la Nación Comentado. Título Preliminar y Libro Primero, Ciudad Autónoma de Buenos Aires (Infojus), 2015, pp. 5-34.

HERRERA, M., «El régimen de divorcio incausado en el Código Civil y Comercial de la Nación», Suplemento Especial de Familia en el Código Civil y Comercial de la Nación (primera parte), diciembre, Buenos Aires (La Ley-Thomson Reuters), 2014, pp. 53-74.

HERRERA, M., «El lugar de la justicia en la ruptura matrimonial según la legislación que se avecina. Bases para leer el régimen de divorcio incausado», en GRAHAM, M. y HERRERA, M. (dirs.), Derecho de las familias, Infancia y Adolescencia. Una mirada crítica y contemporánea, Buenos Aires (Infojus-Ministerio de Justicia y Derechos Humanos de la Nación), 2014, pp. 275-323.

HIGHTON, E., «Una etapa histórica: la mujer en el nuevo Código Civil y Comercial de la Nación», La Ley, 2015. Cita Online: AR/DOC/2598/2015.

HIGHTON, E., «Los jóvenes o adolescentes en el Código Civil y Comercial», La Ley, 2015. Disponible en <http://www.nuevocodigocivil.com/los-jovenes-o- 
adolescentes-en-el-codigo-civil-y-comercial-por-elena-i-highton/>. [Consultado el 23/10/2018].

KEMELMAJER DE CARLUCCI, A., «Capítulo Introductorio», en KEMELMAJER DE CARLUCCI, A., HERRERA, M. y LLOVERAS, N., Tratado de Derecho de familia, Tomo I, Santa Fe (Rubinzal Culzoni), 2014, pp. 9-94.

KEMELMAJER DE CARLUCCI, A., HERRERA, M., LAMM, E. y FERNÁNDEZ, S., El principio de autonomía progresiva en el Código Civil y Comercial. Algunas reglas para su aplicación, Buenos Aires (Infojus), 2015. Disponible en $<$ http://www.saij.gob.ar/aida-kemelmajer-carlucci-principioautonomia-progresiva-codigo-civil-comercial-algunas-reglas-para-su-aplicaciondacf150461-2015-08-18/123456789-0abc-defg1640-51 fcanirtcod >. [Consultado el 16/10/18].

LAMM, E., «El derecho de niños, niñas y adolescentes al cuidado de su propio cuerpo. Una cuestión de autonomía, libertad, integridad, libre desarrollo de la personalidad y dignidad», en FERNÁNDEZ, S. (dir.) Tratado de Derechos de niños, niñas y adolescentes, Tomo I, Buenos Aires (Abeledo Perrot), 2015, pp. 239-299.

LORENZETTI, R., «Comentario a los artículos $1^{\circ}$ y $2^{\circ}$ », en LORENZETTI, R. (dir.), Código Civil y Comercial de la Nación Comentado, Tomo I, Santa Fe (Rubinzal Culzoni), 2014, pp. 26-39.

MOLINA DE JUAN, M., Compensación Económica. Teoría y Práctica, Santa Fe (Rubinzal Culzoni), 2018.

MOLINA DE JUAN, M., «Justicia penal, perspectiva de género y violencia económica», La Ley, Cita Online: AR/DOC/1586/2017.

SALDIVIA MENAJOVSKY, L., «Tomándose la despatologización en serio: el derecho a la identidad de género de niñxs y adolescentes». Revista Interdisciplinaria de Doctrina y Jurisprudencia. Derecho de familia, núm. 82, Buenos Aires (Abeledo Perrot), 2017, Cita Online: AP/DOC/894/2017).

WIERZBA, S., «La salud en el nuevo Código Civil y Comercial de la Nación», (En Letra) - año II, número 4, tomo I, 2015, Dossier sobre el Código Civil y Comercial de la Nación. Disponible en <http://www.fmed.uba.ar/depto/medlegnew/cod1. pdf $>$. [Consultado el 22/10/18]. 